\title{
A REVISED LIST OF THE DIPTERA OF BERMUDA.
}

BY ChaRles W. JOHNSON, BOSTON, MASS.

TrE following list which comprises all previous records, together with several additional species collected by Mr. C. Abbott Davis is brought together to show concisely our present knowledge of the Diptera of the Bermudas, and the work necessary to a more satisfactory condition.

The first recorded Diptera were a few without positive determination in "The Naturalist in Bermuda" by J. Matthew Jones, page I 23:. 1859 . In the "Visitor's Guide to Bermuda" by the same author, 1876 , page 143 , is a list of seven species determined by Baron Osten Sacken, and two by Walker. Dr. P. R. Uhler ("Observations on the insects of the Bermudas,") in "The Bermuda Islands" by Angelo Heilprin pages $15^{2-1} 5^{8}, 1889$, records three species. Dr. Fred. Dahl, "Landfauna of the Bermudas," Plankton Expedition, Vol. I, A, 1892, page 1 09, records about eight species. The most complete account bearing on the Diptera is that given by Prof. A. E. Verrill in his work "The Bermuda Islands," published in the Transaction of the Connecticut Academy of Arts and Sciences, Vol. XI, pages 740-749, 1901-02. In this work about thirty-three are recorded.

The present list contains about fifty species; of this number, fifteen have been added by the collections made by Mr. Davis during a part of July and August, 1903, and one by Mr. T. L. Montgomery in March, 1897 . The fauna seems for the most part to have been derived from the United States and West Indies, and is probably being gradually augmented from these sources. The richness of the flora would indicate a greater number of species and careful collecting at all seasons of the year will undoubtedly add many species to the fauna.

\section{Tipulidae.}

Dicranomyia distans $\mathrm{O}$. S. This seems to be the only species recorded. Prof. Verrill refers to several undetermined species, and Mr. Davis captured Pachyrrhina ferruginea Fabr. on the vessel en route.

\section{Culicidae.}

Culex sollicitans Walk. Several specimens of this and the following species were taken by Mr. Davis, Jüly 24 and 25.

Culex taeniorhynchus Wied., July 25.

Culex fatigans Wied. This species is recorded by Theobald in his Monograph 
of the Culicidae I, p. 28 , from collections made in July, 1899, by Dr. Eldon Harvey.

Stegomyia fasciata (Fabr.). The yellow-fever mosquito. This species, recorded by both Theobald and Verrill, was also taken by Mr. Davis.

\section{Chironomidae.}

Orthocladius, sp. Recorded by Prof. Verrill.

\section{BibIonidaE.}

Dilophus sp. Recorded by J. M. Jones in 1876 . Verrill.

Scatopse atrata Say. Determined by Mr. Coquillett and recorded by Prof.

\section{STRATIOMYidaE.}

Odontomyia sp.? Under this genus two species are referred to by Dr. Uhler.

\section{TABANidaE.}

Tabanus nigrovittatıs Macq. Several specimens were taken by Mr. Davis, July 14-22. This is probably the species referred to by Dr. Uhler as "one of the smaller horse-flies related to $T$. lineola Fabr., but in color resembles the $T$. cincta Fabr."

Tabanus sp. "Of rather large size and with a large green head, is also common"(Verrill).

\section{Asilidae.}

Asilus? sp.? "A Robber-fly belonging to Asilus or some allied genus is described in Miss Hayward's notes" (Verrill).

\section{DOLICHOPODIDAE.}

Sciapus chrysoprasus Walk. The species referred to as "Psilopus chrysoprasinus Wied." by Dr. Fr. Dahl, is undoubtedly the same.

\section{Phoridae.}

Phora sp. Recorded by Prof. Verrill. 


\section{SYRPHIDAE.}

Mesogramma marginatum Say. A number of specimens were collected by Mr. Davis at St. Georges, July 9.

Allograpta obliqua Say. A common species of the islands, obtained by Mr. Davis, July 8-11. Also reported by Mr. Jones in 1876 , and by Prof. Verrill.

Eristalis tenax Linn. One specimen was collected by Mr. Davis on July 10.

Lathyrophthalmus aeneus Scop. Two specimens were taken by Mr. Davis, July 14 and $2 \mathrm{x}$. This species which is more familiarly known as Eristalis aeneus was also collected by Dr. Fr. Dahl in 1892 .

\section{SARCOPhagidae.}

Sarcophaya carnaria Linn. Both Prof. Verrill and Uhler refer specimen to this species. Among the numerous specimens collected by Mr. Davis the true $S$. carnaria is not represented. The specimens are nearer $S$. rabida Walk. also recorded by Prof. Verrill, but the present unsatisfactory condition of our Sarcophagids prevents me from positively determining the species.

Sarcophaga sp.? A smaller form of which a number of specimens were collected by Mr. Davis, July 8.

Helicobia helicis Town. Two specimens were collected by Mr. Davis.

Sarcophagula sp. Recorded by Dr. Dahl.

Calliphora vonititoria Linn. Recorded by Prof. Verrill.

Lucilia sericata Meig. Numerous specimens were collected by Mr. Davis.

Lucilia latifrons Schin. Recorded by Dr. Dahl. and also by Prof. Verrill. Probably only a variety of the preceding.

Lucilia caesar Linn. Recorded by Prof. Verrill.

\section{Muscidae.}

Musca domestica Linn. Common. The smaller form in which yellow is the predominating color of the abdomen is the M. basilaris Macq. It hardly deserves varietal distinction.

Stomoxys calcitrans Linn. Recorded by Prof. Verrill.

\section{ANTHOMYIDAE.}

Ophyra asnescens Wied. A number of specimens were collected by Mr. Davis at St. Georges, July 9 ; also by Mr. T. L. Montgomery in March, 1897. 
Anthomyia lepida Meig. Recorded by Jones, 1876 .

Fannia femorata Loew. Several specimens were collected by Mr. Montgomery in March, 1897 .

Limnophora cyrtonenrina Stein. Obtained by Mr. Davis, July 14.

Mydaea sp. ? One imperfect specimen collected by Mr. Davis July 17.

"Phorbia ceparum = Anthomyia ceparum," "Onion fly." "We were told that this species occurs, but obtained no specimens of it." (Verrill.)

Fucellia fucorum Full. This is probably what is meant by "Incellia fucorine" in Jones' list. Dr. Dahl also refers to a species as Fucellia sp.

\section{Scatophagidae.}

Scatophaga sp. ?. Recorded.

\section{SCIOMYZIDAE.}

Tetanocera spinicornis Loew. Collected by Mr. Mobray, May 30, and by Mr. Davis, July 8.

Tetanocera pictipes Loew. Recorded by Jones in 1876 .

\section{Ortalidae.}

Chatopsis aeneus Wied. Recorded by Jones, 1876 .

\section{TRYPETIDAE.}

Aciura insecta Loew. Two specimens were collected by Mr. Davis at St. Georges, July 9.

Tephritis picciola Bigot. Several specimens were taken by Mr. Davis at St. Georges, July 9. Trypeta humilis Loew, is a synonym.

Ceratitis capitata Wied. "Peach-fly." This species was first recorded from Bermuda by Messrs. Riley and Howard as "A Peach Pest in Bermuda," Insect Life, III, p. 5, figs. 1, 2 ; also p. 120,1890 . This species, which also infests the orange, was probably introduced from Madeira, the nearest locality from which it was previously recorded.

\section{SEPSIDAE.}

Piophila casei Linn. The cheese-fiy. Recorded by Prof. Verrill. 


\section{EPHYDRIDAE.}

Ephydra austrina Coq. One specimen collected by Mr. Davis.

Paratissa pollinosa (Will.). A number of specimens were collected by $\mathrm{Mr}$. Davis, August 5 .

\section{DrosophiLIDAE.}

Drosophila punctulata Loew. A number of specimens were obtained by Mr. Davis at St. Georges, July 9.

Drosophila ampelophila Loew. The fruit-fly. Record by Prof. Verrill as very abundant on decaying fruit, associated with other related species.

\section{Agromyzidae.}

Ophthalmomyia lacteipennis Loew. Two specimens were collected by Mr. Davis at St. Georges, July $2 \mathbf{r}$.

\section{BORBORIDAE.}

Limosina fontinalis Full. One specimen was obtained by Mr. Davis.

Limosina sp. One imperfect specimen, much smaller than the preceding. Dr. Dahl also records an undetermined species found on dead sea-weed.

Diestrammena unicolor in North America. - I have lately received a female of this East Asian spacies which was captured in a greenhouse in Chicago, Ill., from Mr. W. J. Baumgartner. Its congener, marmorata, reported to have established itself in conservatories at Minneapolis, is likewise of Asiatic origin. Both species doubtless owe their introduction to commercial importations of foreign plants, among the wrappings of which they easily secrete themselves. - A. P. MORSE. 

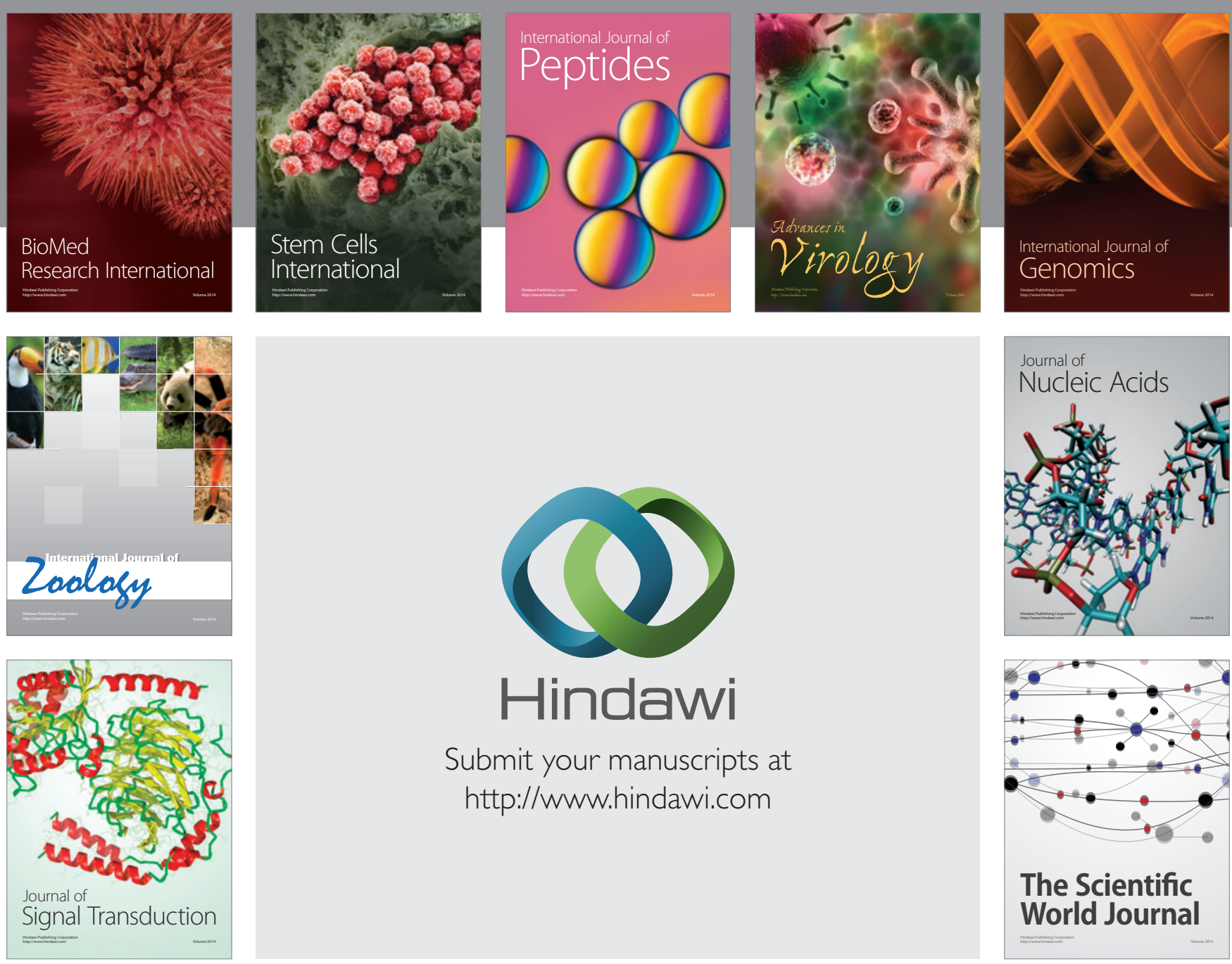

Submit your manuscripts at

http://www.hindawi.com
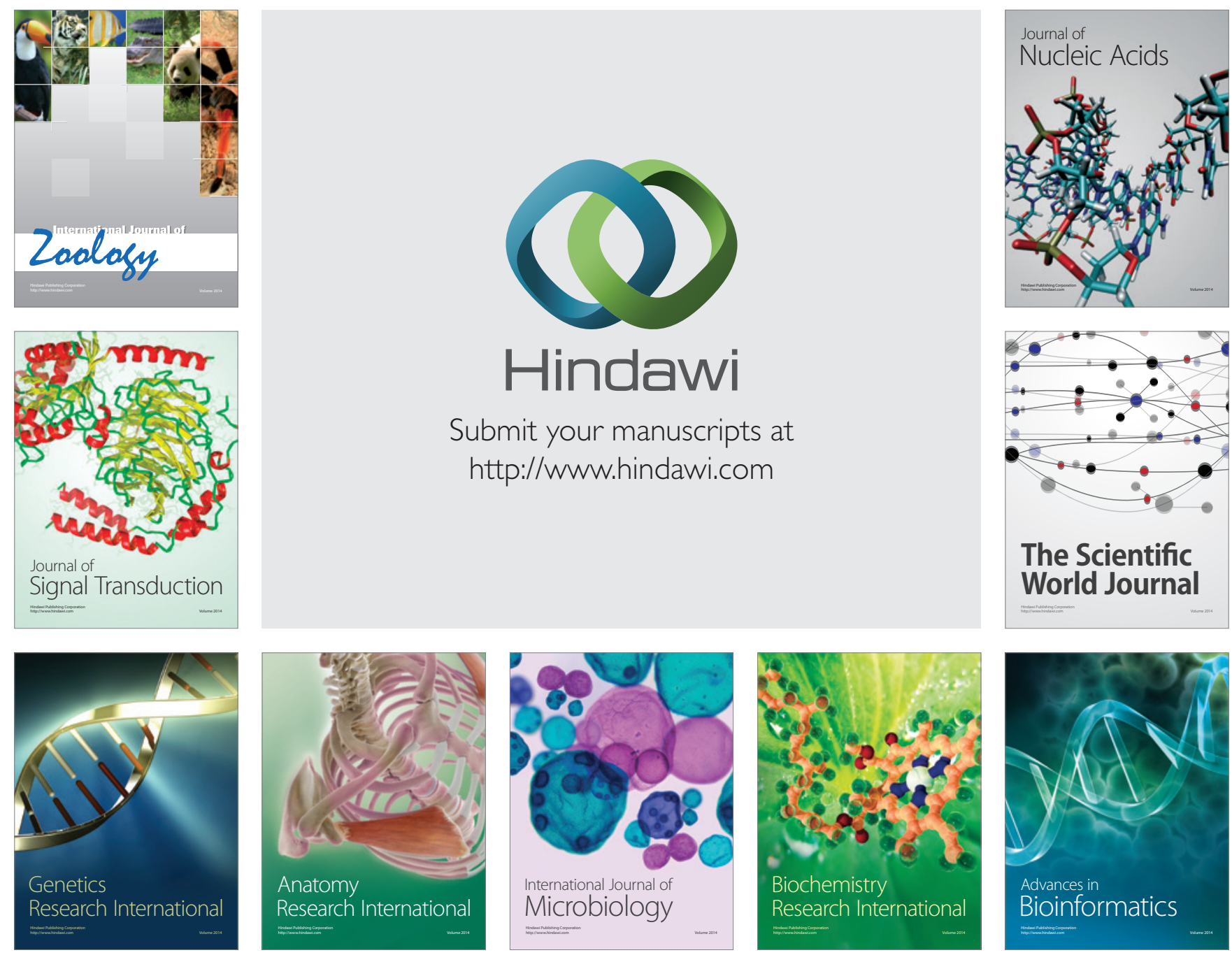

The Scientific World Journal
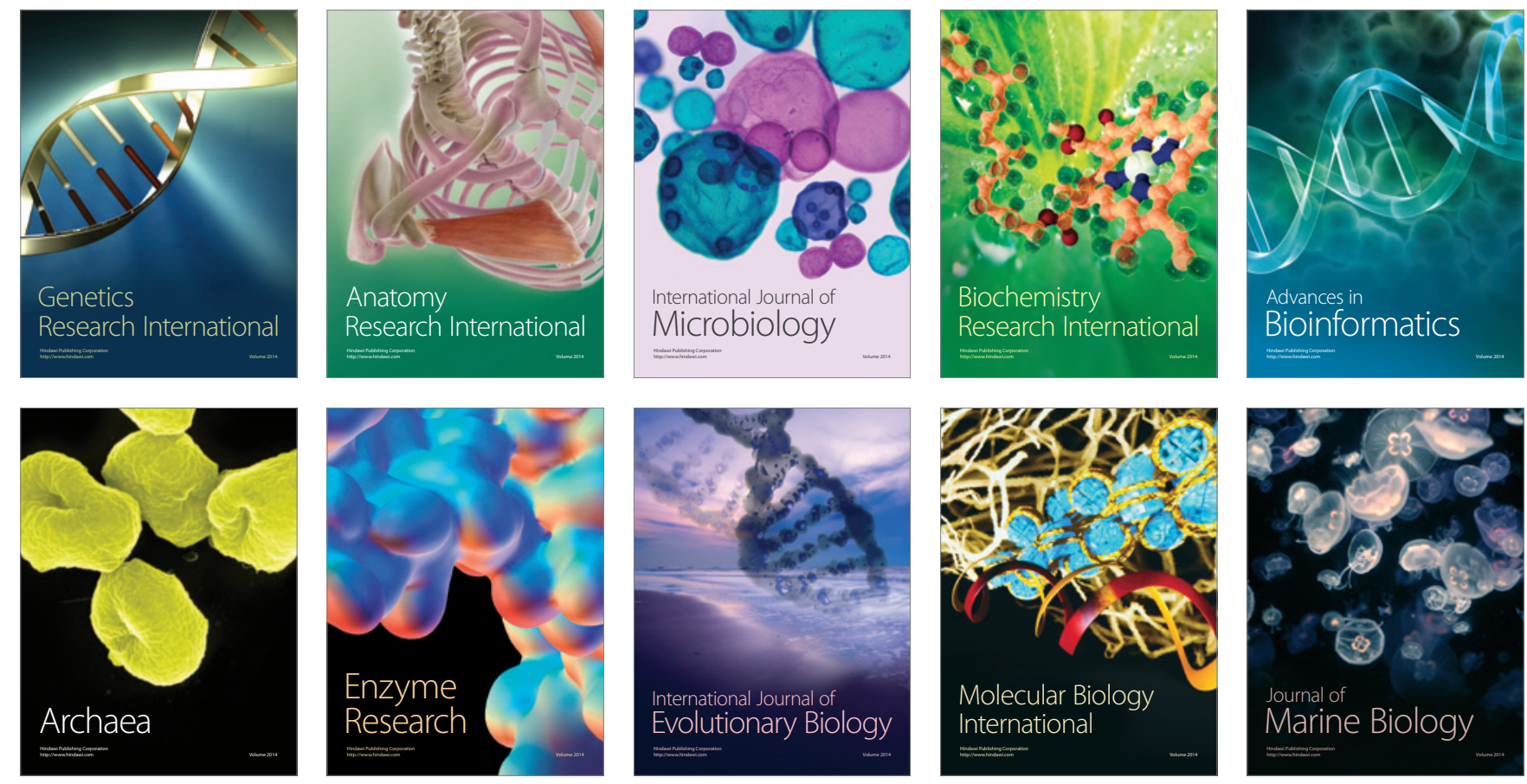